\title{
ATIVIDADES DE INSPEÇÃO E DE MANUTENÇÃO PARA A SUPERESTRUTURA DE UMA PONTE MISTA EM ARCOS METÁLICOS
}

\author{
CHAGAS DOS SANTOS, HUDSON \\ Professor Doutor \\ Instituto Federal do Piauí \\ Piauí; Brasil \\ hudson@ifpi.edu.br
}

\author{
MEDEIROS, CARLOS ALBERTO \\ Professor Mestre \\ Universidade de Mogi das Cruzes \\ São Paulo; Brasil \\ carlosmedeiros@umc.br
}

\section{RESUMO}

As estruturas de pontes são projetadas para atender a requisitos de resistência estrutural e ter comportamento adequado em serviço para um longo período de vida útil da construção. Dessa forma, a elaboração de um programa de inspeção e de manutenção para pontes é de fundamental importância para garantir e preservar os objetivos previstos em projeto. $\mathrm{O}$ presente trabalho descreve o conjunto de atividades de inspeção e de manutenção a serem realizadas para os elementos da superestrutura de uma ponte mista em arcos metálicos de modo a garantir a sua funcionalidade e desempenho estrutural ao longo de sua vida útil. Inicialmente, é apresentado de forma geral os elementos estruturais integrantes da superestrutura da ponte mista em arcos. Em seguida são descritas as atividades de inspeção e de manutenção a serem realizadas para os elementos da superestrutura da ponte mista e elaboradas conforme recomendações de normas e literaturas técnicas.

Palavras-chave: inspeção, manutenção, prevenção, desempenho estrutural, pontes.

\section{ABSTRACT}

Bridge structures are designed to comply with structural strength requirements and have an acceptable performance in service for a long construction life. Thus, it is crucial the elaboration of a bridge inspection and maintenance program in order to guarantee and preserve the designs objectives. The present paper describes the set of inspection and maintenance activities elaborated for a mixed bridge in metallic arches to ensure its functionality and structural performance during your service life. Initially, a general description of the structural system of the mixed bridge in arches is discussed. Finally, the inspection and preventive and corrective maintenance activities, elaborated based on codes and technical references, are presented to be performed on the superstructure elements of the mixed bridge.

Keywords: inspection, maintenance, prevention, structural performance, bridges.

\section{INTRODUÇÃO}

As estruturas de pontes são construídas de modo que sob condições ambientais e de uso previstas em projeto e para um período pré-fixado de vida útil conservem segurança estrutural e apresente comportamento adequado em serviço. Logo, para garantir esses objetivos de projeto é de fundamental importância a elaboração de um programa de inspeção e de manutenção para construções de pontes.

Poças (2009) aponta que os investimentos aplicados em manutenção e conservação de pontes em Portugal devem ser feitos de maneira eficiente. Em sua pesquisa, ele buscou desenvolver metodologias de otimização da durabilidade e da conservação na gestão do ciclo de vida de pontes baseadas em uma análise de custo-benefício e conforme práticas realizadas em outros países, particularmente nos Estados Unidos. Assim, ele propôs um plano de inspeção baseado em tabelas de relação de causa e efeito.

Bolina, Tutikian e Helene (2019) apresenta os conceitos fundamentais relacionados ao estudo de patologia das construções e aborda os tipos de manifestação patológica, os mecanismos de deterioração, diagnósticos e intervenções que podem ser aplicados a estruturas de concreto, metálicas e de madeira. 
No Brasil, a norma NBR 9452 (ABNT, 2016) define as atividades de inspeção programadas para estruturas de pontes, viadutos e passarelas em concreto e que tem como objetivo realizar um exame minucioso da estrutura da obra de arte e consequente elaboração de relatórios de avaliação do estado da obra bem como apresentar recomendações, que podem ser de nova vistoria, de obras de manutenção, de obras de recuperação, de reforço ou de reabilitação.

A norma NBR 9452 (ABNT, 2016) estabelece quatro tipos de periodicidade de inspeção: cadastral, rotineiras, especial e extraordinária. E ela utiliza três parâmetros: funcionais, estruturais e de durabilidade, para emitir uma nota de classificação e que vai de 1 (crítica) a 5 (excelente).

Contudo a norma NBR 9452 é destinada a atividades de inspeção aplicadas a pontes e viadutos em concreto. Dessa forma, Fonseca (2018) propôs uma ficha de inspeção para ser aplicada a estruturas metálicas de pontes ferroviárias. Ele faz uma classificação das manifestações patológicas caracterizadas sob o aspecto estrutural e avalia parâmetros sob o aspecto da corrosão, da condição das ligações e da presenças de trincas para emitir uma nota de classificação da ponte.

O Departamento Nacional de Infraestrutura de Transporte (DNIT) elaborou uma minuta de manual (DNIT, 2016) para orientar a elaboração de atividades de manutenção para obras de arte especias - OAEs. Esse manual descreve como devem ser planejadas e executadas atividades de manutenção preventiva e corretiva para OAEs, baseadas em observações de anomalias nas estruturas, produto de inspeções cadastrais e rotineiras.

O manual do Departamento de Transporte do Estado de Nova York (NYSDOT, 2008) fornece um conjunto de atividades de inspeção e de manutenção para estruturas de pontes. Como resultado das atividades de inspeções é preparado um relatório que apresenta fotos com descrições das anomalias encontradas para os elementos da ponte, uma nota de criticidade e atividades de manutenção preventiva e corretiva a serem executadas para a ponte.

Em se tratando de atividades de inspeção e de manutenção para pontes ferroviárias, Montoya (2016) discute os tipos de manifestações patológicas inspecionáveis e também apresenta as técnicas de manutenção preventiva e corretiva a serem aplicadas na conservação desse tipo de ponte.

O presente trabalho tem como objetivo apresentar um conjunto de atividades de inspeção e de manutenção a serem realizadas para a superestrutura de uma ponte mista em arcos metálicos de modo a garantir a sua funcionalidade e desempenho estrutural ao longo de sua vida útil. Inicialmente, é feita uma descrição geral dos elementos estruturais integrantes da superestrutura da ponte mista em arcos. Em seguida são apresentadas as atividades de inspeção baseadas no registro e classificação de manifestações patológicas para posterior avaliação dos elementos das estruturas metálicas e da laje em concreto do tabuleiro. No final são apresentadas as atividades de manutenção preventiva e corretiva que devem ser realizadas para os elementos da superestrutura da ponte mista.

\section{DESCRIÇÃO DOS ELEMENTOS DA SUPERESTRUTURA DA PONTE MISTA}

A ponte mista em arcos metálicos, mostrada na foto da Figura 1, é constituída por dois arcos paralelos por vão, com quatro vãos de 50m cada, apresentando uma extensão total de 200,0m, com 7,90m de largura e foi construída sobre o Rio Sergipe para atender as Adutoras do Sistema São Francisco.

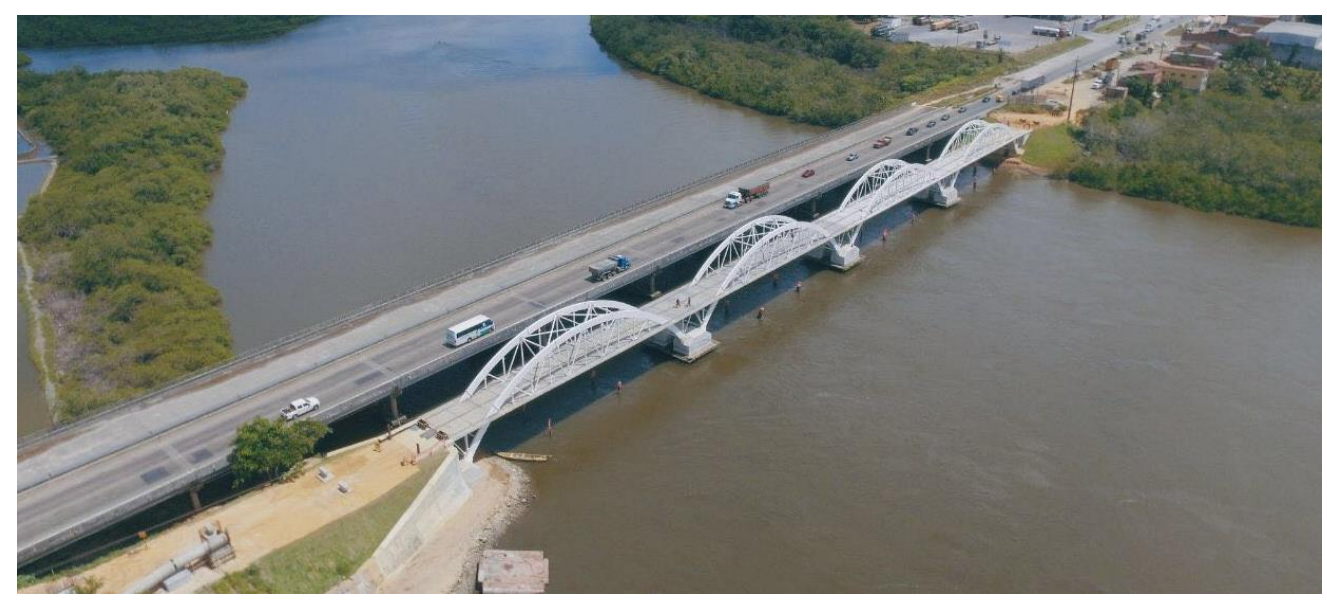

Figura 1: Vista geral da ponte mista. 


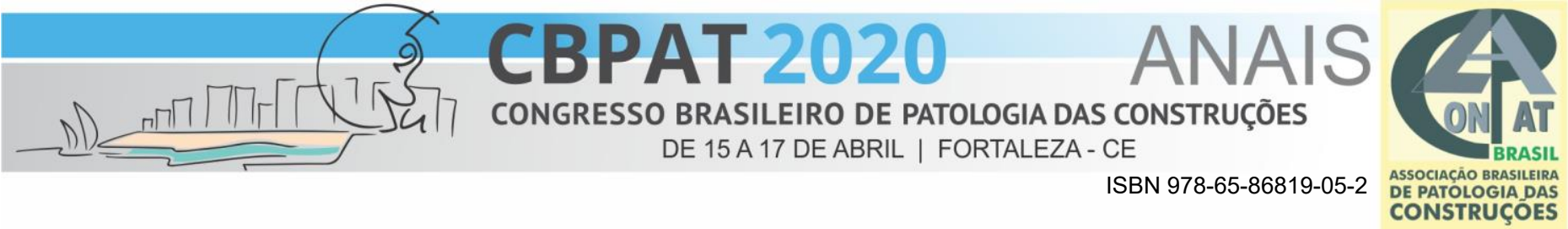

A superestrutura da Ponte Mista é um sistema formado por estruturas metálicas para os elementos de arcos, pendurais, diagonais, vigas longarinas, vigas transversinas e elementos de travamentos; e por laje do tabuleiro em concreto armado, como apresentado nas fotos da Figura 2 e Figura 3, respectivamente.

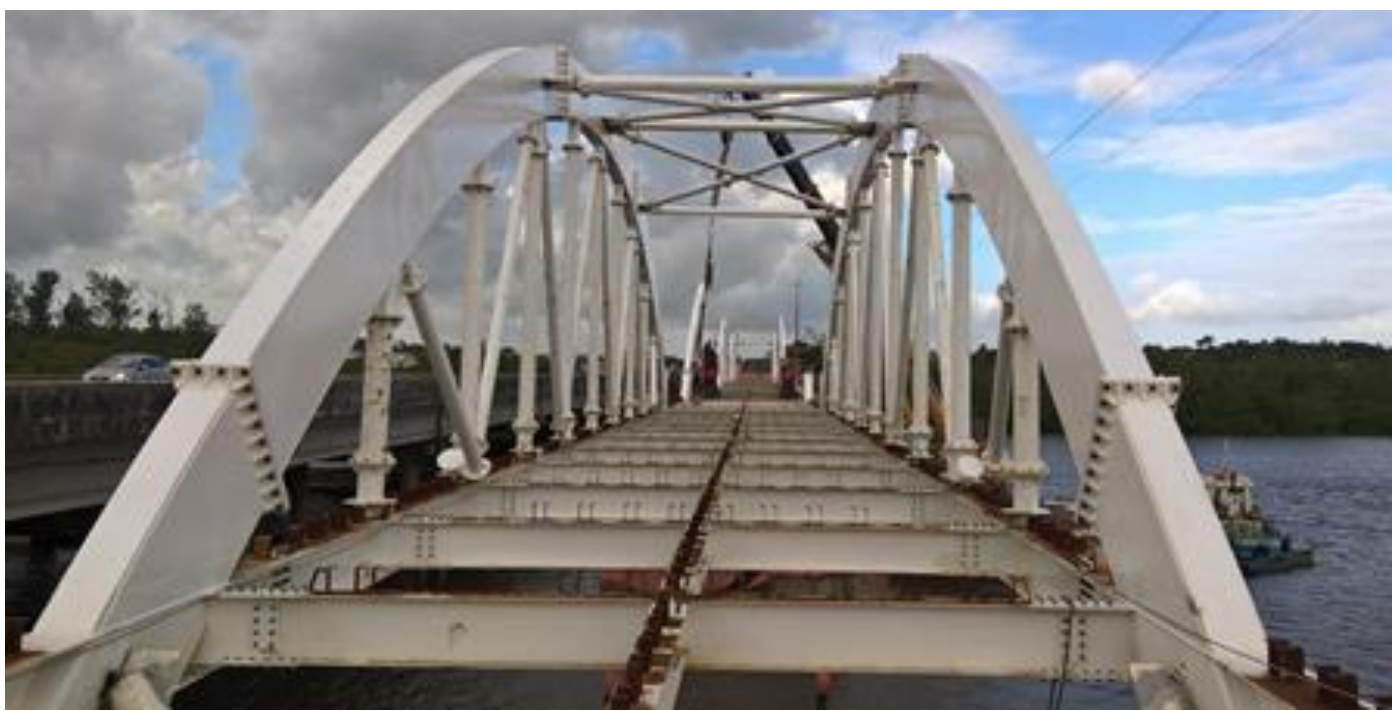

Figura 2: Estruturas metálicas da superestrutura da ponte mista.

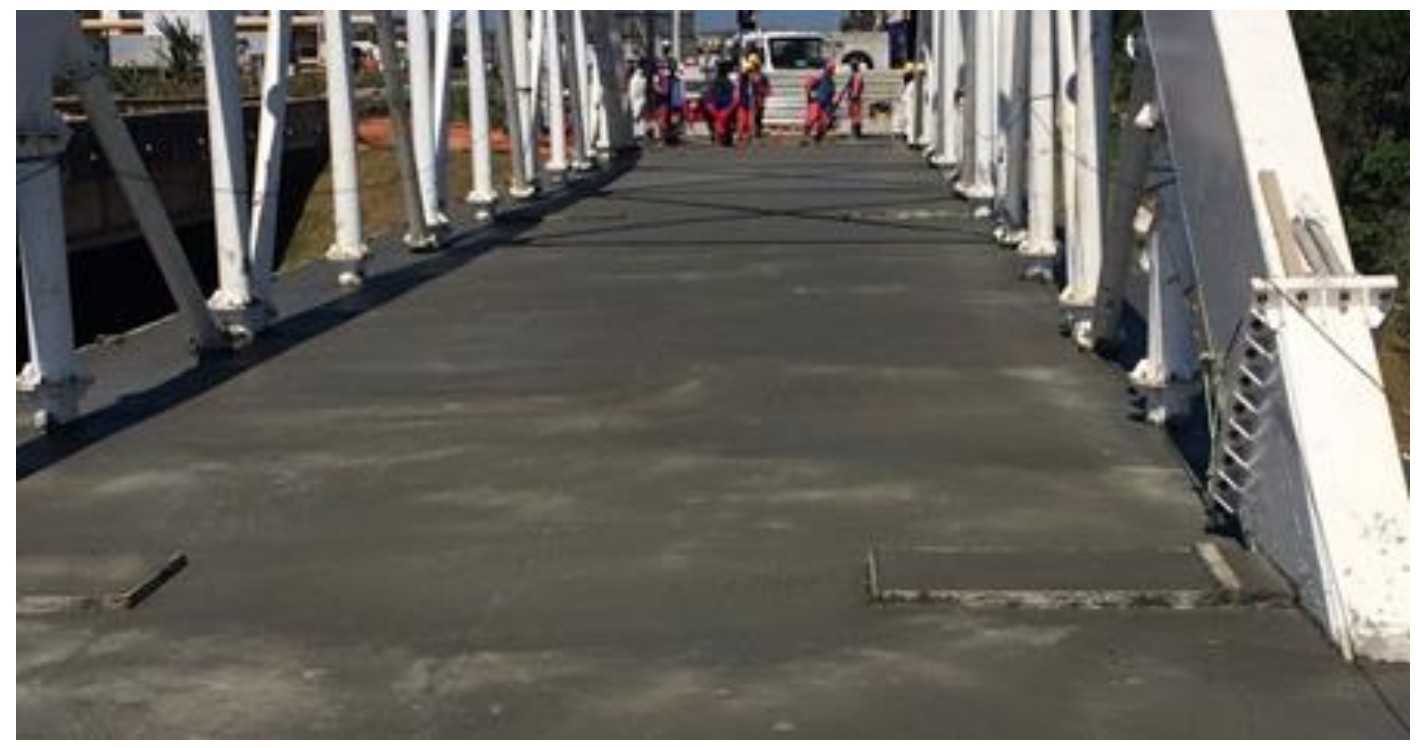

Figura 3: Laje em concreto armado do tabuleiro da ponte mista.

\section{ATIVIDADES DE INSPEÇÃO PARA A SUPERESTRUTURA DA PONTE MISTA}

As atividades de inspeção para a superestrutura da Ponte Mista consiste no prenchimento de uma ficha de inspeção, elaborada conforme os modelos de fichas propostos pela norma NBR 9452 (ABNT, 2016), no caso de estruturas em concreto armado, e por Fonseca (2018), no caso de estruturas metálicas, para atribuir uma nota de classificação da OAE.

Antes do inicio do preenchimento da ficha de inspeção é feita uma classificação para os elementos estruturais da Ponte Mista de acordo com sua relevância na segurança estrutural e conforme três tipos de categorias de elemento: principal, secundário e complementar.

A primeira parte da ficha de inspeção compreende a informações gerais da Ponte Mista, tais como: identificação da localização da ponte, histórico de inspeções e a descrição das intervenções executadas ou em andamento. Enquanto que a segunda parte, refere-se ao registro e classificação de manifestações patológicas identificadas para os elementos estruturais da Ponte Mista. 
As atividades de inspeção para a superestrutura da Ponte Mista é realizada para os elementos constituintes das estruturas metálicas e para a laje em concreto do tabuleiro, conforme descrito a seguir.

\subsection{Estruturas metálicas}

Inicialmente, os elementos das estruturas metálicas da superestrutura da Ponte Mista são inspecionados visualmente para identificar defeitos como categorizados por Costa (2019) em: contaminação, deformação, descontinuidade, deterioração e perda de material.

A nota de classificação da OAE segundo o parâmetro estrutural proposto por Fonseca (2018) é estabelecida por avaliar os elementos das estruturas metálicas sob aspecto da corrosão, da condição das ligações e da presença de trincas, conforme descritos nas tabelas de 1 a 3.

Tabela 1 - Classificação da OAE sob o aspecto da corrosão segundo os parâmetros estrutural e de durabilidade.

\begin{tabular}{|c|c|c|c|}
\hline \multicolumn{4}{|c|}{ Corrosão } \\
\hline $\begin{array}{c}\text { Nota de } \\
\text { classificação }\end{array}$ & Condição & Caracterização es trutural & Caracterização de durabilidade \\
\hline 5 & Excelente & A estrutura não apresenta defeitos. & $\begin{array}{l}\text { A OAE apresenta-se em perfeitas condições, devendo ser } \\
\text { prevista manutenção de rotina. }\end{array}$ \\
\hline 4 & Boa & $\begin{array}{l}\text { Superfície do aço com pouca oxidação ao longo de sua superfície. } \\
\text { A estrutura apresenta danos pequenos e em áreas, sem } \\
\text { comprometer a segurança estrutural. }\end{array}$ & $\begin{array}{l}\text { A OAE apresenta pequenas e poucas anomalias, que } \\
\text { comprometem sua vida útil, em região de baixa agressividade } \\
\text { ambiental. }\end{array}$ \\
\hline 3 & Regular & $\begin{array}{l}\text { Superfície com início de oxidação e da qual a tinta começou a } \\
\text { desprender. } \\
\text { Há perda de seção de até } 5 \% \text { sem comprometimento da } \\
\text { estabilidade da obra. }\end{array}$ & $\begin{array}{l}\text { OAE apresenta pequenas e poucas anomalias, que comprometem } \\
\text { sua vida útil, em região de moderada a alta agressividade } \\
\text { ambiental ou a OAE apresenta moderadas a muitas anomalias, } \\
\text { que comprometem sua vida útil, em região de baixa agressividade } \\
\text { ambiental. }\end{array}$ \\
\hline 2 & Ruim & $\begin{array}{l}\text { Superfície de aço onde toda proteção da superfície foi eliminada e } \\
\text { na qual se observa uma corrosão uniforme generalizada. } \\
\text { Corrosão caracterizada pela formação de placas planas de óxido } \\
\text { de ferro (carepas) que se desprendem da área sob corrosão com } \\
\text { perda de seção de } 5 \% \text { a } 10 \% \text { em elementos principais. }\end{array}$ & $\begin{array}{l}\text { A OAE apresenta anomalias moderadas a abundantes, que } \\
\text { comprometam sua vida útil, em região de alta agressividade } \\
\text { ambiental. }\end{array}$ \\
\hline 1 & Crítica & $\begin{array}{l}\text { Superfície do aço onde se observa uma corrosão atmosférica } \\
\text { severa e generalizada, apresentando pits e alvéolos. } \\
\text { Corrosão caracterizada pela formação intensa de placas, } \\
\text { associada à formação de grumos a partir de várias placas } \\
\text { sobrepostas de óxido de ferro com perda de seção acima de } 10 \% \\
\text { em elementos principais. }\end{array}$ & $\begin{array}{l}\text { A OAE encontra-se em elevado grau de deterioração, apontando } \\
\text { problema já de risco estrutural e/ou funcional. }\end{array}$ \\
\hline
\end{tabular}

Tabela 2 - Classificação da OAE sob o aspecto das ligações e segundo o parâmetro estrutural.

\begin{tabular}{|c|c|c|}
\hline \multicolumn{3}{|r|}{ Ligações } \\
\hline $\begin{array}{c}\text { Nota de } \\
\text { classificação }\end{array}$ & Condição & Caracterização es trutural \\
\hline 5 & Excelente & A ligação não apresenta defeitos \\
\hline 4 & Boa & $\begin{array}{l}\text { Ocorrência de sinais de movimentação ou corrosão em até } 1 / 6 \text { dos parafusos/rebites em } \\
\text { ligação de elemento estrutural principal. }\end{array}$ \\
\hline 3 & Regular & $\begin{array}{l}\text { Ocorrência de deficiência na ligação que não há sinais de comprometimento da estabilidade } \\
\text { da obra. Ocorrência de sinais de movimentação ou corrosão em mais de } 1 / 6 \text { dos } \\
\text { parafusos/rebites em ligação de elemento estrutural principal. }\end{array}$ \\
\hline 2 & Ruim & $\begin{array}{l}\text { Ocorrência de danos na ligação que comprometam a segurança estrutural da OAE, sem risco } \\
\text { iminente. Perda de até } 1 / 6 \text { dos parafusos/rebites em ligação de elemento estrutural principal. } \\
\text { Ocorrência de trinca em elemento ou meio de ligação com redundância ou de elemento } \\
\text { estrutural secundário. }\end{array}$ \\
\hline 1 & Crítica & $\begin{array}{l}\text { Ocorrência de falha grave em ligações de elementos estruturais principais com risco de } \\
\text { colapso estrutural. Perda de mais de } 1 / 6 \text { dos parafusos/rebites da ligação. } \\
\text { Ocorrência de trinca em elemento ou meio de ligação sem redundância ou de elemento } \\
\text { estrutural principal. }\end{array}$ \\
\hline
\end{tabular}

Tabela 3 - Classificação da OAE sob o aspecto das trincas segundo o parâmetro estrutural. 


\begin{tabular}{|c|c|c|}
\hline \multicolumn{3}{|r|}{ Trincas } \\
\hline $\begin{array}{c}\text { Nota de } \\
\text { classificação }\end{array}$ & Condição & Caracterização estrutural \\
\hline 5 & Excelente & Não apresenta trincas. \\
\hline 4 & Boa & Ocorrência de trincas em fase inicial em elemento estrutural secundário com redundância. \\
\hline 3 & Regular & $\begin{array}{l}\text { Ocorrência de trincas em fase inicial em elemento estrutural secundário sem redundância. } \\
\text { Ocorrência de trincas em fase avançada em elemento estrutural secundário com redundância. }\end{array}$ \\
\hline 2 & Ruim & $\begin{array}{l}\text { Ocorrência de trincas em fase avançada em elemento estrutural secundário sem redundância. } \\
\text { Ocorrência de trincas em fase inicial em elemento estrutural principal com redundância. }\end{array}$ \\
\hline 1 & Crítica & $\begin{array}{l}\text { Ocorrência de trincas em elemento estrutural principal sem redundância. } \\
\text { Ocorrência de trincas em fase avançada em elemento estrutural principal com redundância. }\end{array}$ \\
\hline
\end{tabular}

A ficha de inspeção que deve ser preenchida na avaliação das anomalias encontradas para os elementos das estruturas metálicas da superestrutura da Ponte Mista e para a classificação da OAE é mostrada na Figura 4.

Figura 4: Ficha de inspeção para avaliação dos elementos das estruturas metálicas da superestrutura da Ponte Mista e classificação da OAE.

\begin{tabular}{|c|c|c|c|}
\hline \multicolumn{4}{|c|}{ Caracterização Es trutural } \\
\hline \multirow{2}{*}{ Elementos } & \multicolumn{3}{|c|}{ Anomalias } \\
\hline & Corrosão & Ligações & Trincas \\
\hline \multicolumn{4}{|l|}{ Arcos } \\
\hline \multicolumn{4}{|l|}{ Vigas longarinas } \\
\hline \multicolumn{4}{|l|}{ Vigas transversinas } \\
\hline \multicolumn{4}{|l|}{ Diagonais } \\
\hline \multicolumn{4}{|l|}{ Pendurais } \\
\hline \multicolumn{4}{|l|}{ Elementos de travamento superior } \\
\hline \multicolumn{4}{|l|}{ Elementos de travamento superior } \\
\hline \multicolumn{4}{|c|}{ Observações } \\
\hline
\end{tabular}

\subsection{Laje em concreto do tabuleiro}

As atividades de inspeção realizada para a laje em concreto do tabuleiro da Ponte Mista documenta as ocorrências sob o aspecto estrutural e para as anomalias de corrosão das armaduras, estado de fissuração, cobrimento insuficiente, eflorescência, desplacamentos, entre outros.

A ficha de inspeção adotada para a laje em concreto do tabuleiro da Ponte Mista segue o roteiro básico apresentado no Anexo B da norma NBR 9452 (ABNT, 2016) e adota os critérios de classificação de manifestações patológicas, recomendações de terapia e nota de classificação da OAE para os parâmetros estrutural, funcional e de durabilidade conforme definidos na mesma norma.

\section{ATIVIDADES DE MANUTENÇÃO PARA A SUPERESTRUTURA DA PONTE MISTA}

As atividades de manutenção previstas para os elementos das estruturas metálicas e da laje em concreto do tabuleiro da superestrutura da Ponte Mista foram elaboradas com base nas recomendações técnicas descritas no manual de Manutenção de Obras de Arte Especiais (DNIT, 2016). 
Antes da realização de cada atividade de manutenção deve ser feita uma inspeção geral do elemento em que serão executados os trabalhos, identificando os serviços necessários e os quantitativos dos mesmos de modo a estabelecer um plano de ação e tarefas com responsabilidades para todos envolvidos na atividade de manutenção.

\subsection{Estruturas metálicas}

A manutenção a ser realizada para as estruturas metálicas da superestrutura da Ponte Mista constituídas dos elementos de arcos, pendurais, diagonais, barras de travamentos, vigas longarinas, vigas transversinas, elementos de proteção de guarda corpo e das ligações parafusadas e soldadas deve ser realizada com o intuito de evitar a ocorrência da corrosão para esses elementos e consequente perda de área efetiva de resistência estrutural.

Em relação as ligações parafusadas e soldadas, a manutenção deve ser realizada de modo a garantir que essas ligações permaneçam trabalhando corretamente, ou seja, transferindo força integralmente entre os elementos estruturais.

As atividades de manutenção a serem realizadas para os elementos das estruturas metálicas da superestrutura da Ponte Mista são descritas a seguir.

\subsubsection{Pintura de elementos metálicos}

\begin{tabular}{|c|c|}
\hline TIPO & enção preventiva. \\
\hline OBJETIVO & Prevenir a corrosão e a perda de área efetiva dos elementos, especialmente estruturais. \\
\hline FREQUÊNCIA & Segundo recomendações do fabricante da tinta. \\
\hline TRABALHOS & $\begin{array}{l}\text { - Realizar limpeza mecânica das superfícies, removendo cascas de laminação ou } \\
\text { impurezas, com o uso de aparelhos mecânicos, lixadoras, escovas metálicas. As rebarbas } \\
\text { e resíduos de solda devem ser retiradas com equipamento mecânico (talhadeira). } \\
\text { - Remoção de óleo ou graxa utilizando soluções químicas adequadas e não toxicas, se } \\
\text { necessário. } \\
\text { - Aplicar jateamento abrasivo (granalha de aço, oxido de alumínio, microesferas de vidro, } \\
\text { - } \text { hidrojateamento a ultra pressão, etc.). } \\
\text { - Apliminar a poeira residual com jato de ar, escova ou aspirador de pó. } \\
\text { - } \text { base para a pintura definitiva. } \\
\text { - Aplicar a pintura de revestimento, garantindo a aderência com a camada anterior, em até } \\
\text { duas mãos. A segunda mão deverá ser aplicada após } 72 \text { horas, salvo recomendação do } \\
\text { fabricante. }\end{array}$ \\
\hline OBSERVAÇÕES & $\begin{array}{l}\text { - Evitar o uso de métodos abrasivos de limpeza, os quais podem aumentar a perda de área } \\
\text { efetiva dos materiais. } \\
\text { - Antes do início dos trabalhos deverá ser estabelecido e aprovado o sistema de contenção } \\
\text { ou fechamento da área de pintura, com o objetivo de evitar que subprodutos do processo } \\
\text { sejam transportados pelas correntes de vento ou que possam contaminar corpos de água. } \\
\text { - A aplicação da pintura não deverá ser executada em dia chuvoso. } \\
\text { - As tintas para pintura de primeira demão e de revestimento poderão ser feitas a base de } \\
\text { esmaltes sintéticos, à base de borracha clorada ou epóxi. }\end{array}$ \\
\hline REFERÊECIA & $\begin{array}{l}\text { - Manual do Departamento de Transporte do Estado de Nova York (NYSDOT, 2008), } \\
\text { Item 3. CYCLICAL PREVENTIVE MAINTENANCE PROCEDURES - PAINTING } \\
\text { BRIDGE STEEL. }\end{array}$ \\
\hline
\end{tabular}

4.1.2 Reparos das ligações de parafusos que estejam danificados ou com folgas

\begin{tabular}{|l|l|}
\hline TIPO & Manutenção corretiva. \\
\hline OBJETIVO & Recuperar a capacidade de transferência de forças prevista para a ligação parafusada. \\
\hline FREQUÊNCIA & De acordo com o resultado de inspeção rotineira ou especial. \\
\hline TRABALHOS & $\bullet \quad$ Identificar os parafusos danificados ou com folgas. \\
& $\bullet \quad$ Reaplicar torque de aperto nos parafusos que estejam com pequenas folgas. \\
& $\bullet \quad$ Retirar os parafusos danificados ou com folga excessiva e substituir por parafusos novos. \\
\hline
\end{tabular}




\begin{tabular}{|l|l|l|}
\hline & $\bullet \quad$ Pintar imediatamente os parafusos reparados conforme orientações de 4.1.1. \\
\hline OBSERVAÇÕES & $\bullet \begin{array}{l}\text { Para os parafusos que devem ser novamente reapertados, deve-se aplicar o torque de } \\
\text { aperto conforme previsto pelo fabricante do parafuso. }\end{array}$ \\
& $\begin{array}{l}\text { Para os parafusos danificados ou com folgas excessivas a serem substituídos, a } \\
\text { substituição por parafusos novos deve ser feita de modo a garantir as características } \\
\text { estruturais previstas em projeto e atender as recomendações de instalação indicadas pelo } \\
\text { fabricante do parafuso. }\end{array}$ \\
\hline REFERÊENCIA & $\begin{array}{l}\text { Manual do Departamento de Transporte do Estado de Nova York (NYSDOT, 2008), } \\
\text { Item 4. CORRECTIVE PREVENTIVE MAINTENANCE PROCEDURES - } \\
\text { REPAIRING/REPLACING STEEL MEMBERS. }\end{array}$ \\
\hline
\end{tabular}

4.1.3 Reparos das ligações soldadas que estejam danificadas

\begin{tabular}{|c|c|}
\hline TIPO & Manutenção corretiva. \\
\hline OBJETIVO & Recuperar a capacidade estrutural da junta soldada. \\
\hline FREQUÊNCIA & De acordo com o resultado de inspeção rotineira ou especial. \\
\hline TRABALHOS & $\begin{array}{l}\text { - Identificar as soldas danificadas. } \\
\text { - Retirar o metal de solda danificado e refazer o cordão de solda. } \\
\text { - Pintar imediatamente as juntas soldadas reparadas conforme orientações de 4.1.1. }\end{array}$ \\
\hline OBSERVAÇÕES & $\begin{array}{l}\text { - Os reparos realizados para as soldas danificadas devem ser feitos de modo a garantir as } \\
\text { características estruturais previstas em projeto. }\end{array}$ \\
\hline REFERÊNCIA & $\begin{array}{l}\text { - Manual do Departamento de Transporte do Estado de Nova York (NYSDOT, 2008), } \\
\text { Item 4. CORRECTIVE PREVENTIVE MAINTENANCE PROCEDURES - } \\
\text { REPAIRING/REPLACING STEEL MEMBERS. }\end{array}$ \\
\hline
\end{tabular}

4.1.4 Tratamento de trincas em elementos das estruturas metálicas

\begin{tabular}{|c|c|}
\hline TIPO & Manutenção corretiva. \\
\hline OBJETIVO & $\begin{array}{l}\text { Eliminar trincas presentes em elementos das estruturas metálicas de modo a preservar a } \\
\text { durabilidade a fadiga da estrutura. }\end{array}$ \\
\hline FREQUÊNCIA & De acordo com o resultado de inspeção rotineira ou especial. \\
\hline TRABALHOS & $\begin{array}{l}\text { - Identificar as regiões com presença de trincas nos elementos estruturais e nas ligações } \\
\text { - Remorasadas e juntas soldadas. } \\
\text { - } \quad \text { Pintar imediatamente a junta soldada reparada conforme orientações de 4.1.1. }\end{array}$ \\
\hline OBSERVAÇÕES & $\begin{array}{l}\text { - No reparo executado para as juntas soldadas, deve-se inicialmente aprovar um } \\
\text { procedimento de soldagem para autorização da realização dos trabalhos de reparos das } \\
\text { estruturas metálicas. } \\
\text { - No reparo executado para ligações parafusadas, chapas metálicas e para perfis metálicos, } \\
\text { recomenda-se a realização de um reparo por reforço estrutural ou uma troca das partes } \\
\text { danificadas da estrutura metálica. E com posterior pintura do elemento reparado } \\
\text { conforme orientações de 4.1.1. }\end{array}$ \\
\hline REFERÊNCIA & $\begin{array}{l}\text { - Manual do Departamento de Transporte do Estado de Nova York (NYSDOT, 2008), } \\
\text { Item 4. CORRECTIVE PREVENTIVE MAINTENANCE PROCEDURES - } \\
\text { REPAIRING/REPLACING STEEL MEMBERS. }\end{array}$ \\
\hline
\end{tabular}

\subsection{Laje em concreto do tabuleiro}

A seguir são descritas as atividades de manutenção a serem realizadas para a laje em concreto do tabuleiro da superestrutura da Ponte Mista.

\subsubsection{Limpeza das superfícies expostas da laje do tabuleiro}

\begin{tabular}{|l|l|}
\hline TIPO & Manutenção programada. \\
\hline OBJETIVO & $\begin{array}{l}\text { Garantir a limpeza do tabuleiro e a conservação da superfície de rolamento, para } \\
\text { continuidade do tráfego e a segurança aos usuários.. }\end{array}$ \\
\hline
\end{tabular}




\begin{tabular}{|c|c|}
\hline FREQUÊNCIA & A cada dois anos. \\
\hline TRABALHOS & $\begin{array}{l}\text { - Proteger as bordas da ponte para evitar contaminação de corpos de água com resíduos da } \\
\text { lavagem ou danos em estruturas vizinhas. } \\
\text { - Remover os detritos, material vegetativo e materiais estranhos, com ferramentas } \\
\text { manuais ou mecânicas, evitando a danificação dos outros elementos. } \\
\text { - Retirar da área deste elemento colônias de insetos que podem afetar a estrutura, } \\
\text { segurança e comodidade dos usuários. } \\
\text { - Limpar todas as superfícies expostas com água limpa a jato, regulando a pressão para } \\
\text { que ela não danifique o concreto da laje ou outros materiais. } \\
\text { - Complementar a limpeza das superfícies de concreto expostas, com as indicações } \\
\text { contidas na norma DNIT 081/2006-ES, especialmente no que refere a remoções } \\
\text { superficiais, manchas e eflorescências. }\end{array}$ \\
\hline OBSERVAÇÕES & $\begin{array}{l}\text { - Nos processos de lavagem com jato, ter precaução com lascas de tinta que possam se } \\
\text { soltar. Elas devem ser coletadas e descartadas corretamente. Além disso, prevenir que os } \\
\text { sedimentos e materiais produzidos na limpeza descarreguem diretamente em rios ou } \\
\text { outros corpos de água. } \\
\text { - Em eflorescências pode-se proceder inicialmente com limpeza com escova e água. Caso } \\
\text { não se obtenha sucesso, pode-se executar lavagem da área com escova e ácido clorídrico } \\
\mathrm{HCl} \text {, diluído em proporção } 1: 10 \text {, sem exceder a quantidade de } \mathrm{HCl} \text { de } 150 \mathrm{~g} / \mathrm{m}^{2} \text {. }\end{array}$ \\
\hline REFERÊI & $\begin{array}{l}\text { - Manual do Departamento de Transporte do Estado de Nova York (NYSDOT, 2008), } \\
\text { Item 3. CYCLICAL PREVENTIVE MAINTENANCE PROCEDURES - BRIDGE } \\
\text { CLEANING. }\end{array}$ \\
\hline
\end{tabular}

4.2.2 Limpeza e restauração de concreto atacado pela corrosão

\begin{tabular}{|c|c|}
\hline TIPO & Manutenção corretiva. \\
\hline OBJETIVO & $\begin{array}{l}\text { Restaurar a integridade estrutural de elementos de concreto, garantir o retiro do material } \\
\text { contaminado e evitar que o dano progrida. }\end{array}$ \\
\hline FREQUÊNCIA & Sob demanda. \\
\hline TRABALHOS & $\begin{array}{l}\text { - Definir a área a ser tratada, delimitando um contorno geométrico linear da área a ser } \\
\text { recuperada, segundo indicações da inspeção. } \\
\text { - Cortar com serra circular de segmentos adiamantados a área delimitada e marcada, } \\
\text { garantindo cortes retos. } \\
\text { - Remover todo o concreto contaminado ao redor da armadura com corrosão, utilizando } \\
\text { jateamento abrasivo (granalha de aço, óxido de alumínio, microesferas de vidro, } \\
\text { hidrojateamento a ultra pressão, etc.) ou ferramentas adequadas (martelos mecânicos, } \\
\text { ponteiros, etc.) para não induzir microfissuras no concreto e para não prejudicar ainda } \\
\text { mais a armadura ou sua aderência ao concreto. } \\
\text { - Deverá ser realizado o retiro de todo material ao longo das laterais das barras da } \\
\text { armadura corroída, garantindo que a sua extensão não se encontre imersa no concreto } \\
\text { contaminado, o que poderia ocasionar um processo de corrosão ainda mais rápido e } \\
\text { agressivo. } \\
\text { - Garantir na remoção, um espaço livre do concreto situado ao redor das barras expostas } \\
\text { de no mínimo } 2 \text { cm, visando garantir o acesso para limpeza das barras da armadura, } \\
\text { assim como, permitir um adequado comprimento de ancoragem. } \\
\text { - Limpar cuidadosamente as barras corroídas, com escova de aço para pequenas áreas ou } \\
\text { jateamento abrasivo para grandes áreas. } \\
\text { Examinar cuidadosamente as barras corroídas e já limpas, para avaliação da perda da sua } \\
\text { capacidade resistente; se a perda for superior a 10\%, as barras devem ser suplementadas. } \\
\text { Para realização de emendas nas armaduras, estas poderão ser realizadas por traspasse; } \\
\text { por luvas com preenchimento metálico, rosqueadas ou prensadas, ou por solda. Outros } \\
\text { tipos de emendas deverão ser justificados e aprovados por Engenheiro Especialista. } \\
\text { Após a remoção de todos os detritos, a armadura tratada e a suplementar, se esta for } \\
\text { necessária, devem ser pintadas com tinta especial anti-ferruginosa. } \\
\text { Deverão realizar-se os procedimentos necessários para garantir a aderência entre o } \\
\text { concreto in loco e o concreto novo (passivação da armadura, construção de ponte de }\end{array}$ \\
\hline
\end{tabular}




\begin{tabular}{|l|l|}
\hline & aderência, saturação da superfície de concreto, etc.). \\
\hline OBSERVAÇÕES & $\begin{array}{l}\text { Outras indicações a serem atendidas estão contidas na norma DNIT 084/2006-ES, para } \\
\text { tratamento de corrosão. }\end{array}$ \\
\hline REFERÊNCIA & $\begin{array}{l}\text { Manual do Departamento de Transporte do Estado de Nova York (NYSDOT, 2008), } \\
\text { Item 4. CORRECTIVE PREVENTIVE MAINTENANCE PROCEDURES - } \\
\text { REPAIRING THE CONCRETE DECK. }\end{array}$ \\
\hline
\end{tabular}

\subsubsection{Selagem de trincas e fissuras em concreto}

\begin{tabular}{|l|l|}
\hline TIPO & Manutenção preventiva. \\
\hline OBJETIVO & $\begin{array}{l}\text { Aplicar material selante em fissuras de tabuleiros de concreto, minimizando o ingresso de } \\
\text { água através destas descontinuidades. }\end{array}$ \\
\hline FREQUÊNCIA & A cada dois anos. \\
\hline TRABALHOS & $\begin{array}{l}\text { Soltar e retirar depósitos de sujeira ou materiais depositados e limpar com ar } \\
\text { comprimido, evitando o uso de água que pode diminuir a capacidade selante do material } \\
\text { a utilizar. } \\
\text { Realizar a abertura das trincas ou fissuras, preferentemente com sulcos em forma de "V" } \\
\text { sobre toda a extensão das fissuras e nas duas faces da peça (caso esta atravesse a seção, } \\
\text { com o uso de uma cortadora de concreto ou de serras circulares com segmentos } \\
\text { adiamantados), atingindo uma profundidade que garanta o concreto sadio. }\end{array}$ \\
\hline $\begin{array}{l}\text { Limpar a área e retirar os escombros do processo de abertura da fissura. } \\
\text { Preparar as trincas ou fissuras a ser reparadas utilizando jateamento abrasivo (granalha } \\
\text { de aço, oxido de alumínio, microesferas de vidro, hidrojateamento a ultra pressão, etc.). } \\
\text { Limpar de novo toda a superfície da trinca ou fissura, antes de aplicar o material selante, } \\
\text { garantindo que tenha sido dissipado o calor gerado no processo de corte. } \\
\text { Aplicar o material selante (preferentemente resina de baixa viscosidade), de acordo com } \\
\text { as instruções do fabricante, e da norma DNIT 083/2006-ES, garantindo especialmente os } \\
\text { tempos de secagem ou curado. } \\
\text { Evitar a aplicação em excesso do material selante, retirando o sobrante. }\end{array}$ \\
\hline OBSERVAÇÕES & $\begin{array}{l}\text { São consideradas fissuras as aberturas com até 0,5 mm, as maiores de 0,5 mm e menores } \\
\text { de 1,0 mm são chamadas de trincas. }\end{array}$ \\
\hline O procedimento pode ser utilizado tanto em fissuras longitudinais quanto em \\
transversais.
\end{tabular}

4.2.3 Remendos em concreto

\begin{tabular}{|l|l|}
\hline TIPO & Manutenção preventiva. \\
\hline OBJETIVO & Restaurar a integridade estrutural do elemento de concreto da laje do tabuleiro. \\
\hline FREQUÊECIA & Segundo resultado da inspeção rotineira ou especial. \\
\hline TRABALHOS & $\begin{array}{l}\text { Identificar e marcar a área danificada, a qual deverá corresponder com um retângulo ou } \\
\text { quadrado. A área deverá incluir pelo menos } 15 \mathrm{~cm} \text { a mais da fissura ou da anamolia } \\
\text { detectada. }\end{array}$ \\
& $\begin{array}{l}\text { Cortar com serra circular de segmentos adiamantados a área danificada e marcada, } \\
\text { garantindo cortes retos, evitando realizar cortes na armadura existente. Nas esquinas da } \\
\text { área de corte deve-se garantir que não sejam induzidas superfícies posteriores de } \\
\text { desprendimento. Sugere-se realizar este último trecho de corte manualmente sem o uso } \\
\text { da serra. }\end{array}$ \\
& $\begin{array}{l}\text { Retirar o material deteriorado usando martelos pneumáticos e ferramentas manuais até } \\
2,5 \text { a } 3,0 \text { cm cm por baixo da armadura existente. } \\
\text { Limpar a área utilizando jato de água. } \\
\text { Limpar o aço exposto com jateamento abrasivo (granalha de aço, oxido de alumínio, } \\
\text { microesferas de vidro, hidrojateamento a ultra pressão, etc.) ou com escova metálica }\end{array}$ \\
\hline
\end{tabular}




\begin{tabular}{|c|c|}
\hline & $\begin{array}{l}\text { para remover a ferrugem ou outros contaminantes. } \\
\text { Dispor armadura adicional, para recuperar perdas de seção se estas foram superiores ou } \\
\text { iguais ao } 20 \% \text {. Para realização de emendas nas armaduras, estas poderão ser realizadas } \\
\text { por traspasse; por luvas com preenchimento metálico, rosqueadas ou prensadas, ou por } \\
\text { solda. Outros tipos de emendas deverão ser justificados e aprovados por Engenheiro } \\
\text { Especialista. } \\
\text { - Aplicar material ligante ou umedecer a superfície de concreto remanente para garantir a } \\
\text { adesão com o novo. } \\
\text { - Colocar o novo concreto ou material de remendo (por exemplo epóxi), segundo o reparo } \\
\text { seja parcial ou na espessura total do tabuleiro. } \\
\text { Nivelar o concreto e realizar o acabamento adequado, liso ou corrugado, segundo a } \\
\text { superfície de rolamento a dispor. } \\
\text { - Providenciar adequada cura para o concreto, evitando rachaduras. }\end{array}$ \\
\hline OBSERVAÇÕES & $\begin{array}{l}\text { - A recomendação aqui apresentada é adotada para reparos menores nos quais não é } \\
\text { observado comprometimento estrutural do tabuleiro. Estes devem ser identificados nas } \\
\text { inspeções rotineiras. } \\
\text { - Outras indicações a serem atendidas estão contidas na norma do DNIT 081/2006-ES, } \\
\text { para remoções superficiais com corte. } \\
\text { - Reparos maiores, deverão ser avaliados por especialista estrutural, em inspeção especial } \\
\text { ou intermediária. }\end{array}$ \\
\hline REFERÊNCIA & $\begin{array}{l}\text { - Manual do Departamento de Transporte do Estado de Nova York (NYSDOT, 2008), } \\
\text { Item 4. CORRECTIVE PREVENTIVE MAINTENANCE PROCEDURES - LOW } \\
\text { VOLUME SHOTCRETE. }\end{array}$ \\
\hline
\end{tabular}

\section{CONCLUSÃO}

O presente trabalho descreveu as atividades de inspeção e de manutenção a serem realizadas para a superestrutura de uma ponte mista em arcos metálicos de modo a garantir a sua funcionalidade e desempenho estrutural ao longo de sua vida útil.

Inicialmente foram descritas as atividades de inspeção para a superestrutura da ponte mista e que consiste no preenchimento de uma ficha de inspeção de modo a possibilitar uma classificação das manifestações patológicas e estabelecimento de uma nota de classificação da ponte. Foi abordado que no caso da classificação das manifestações patológicas encontradas para os elementos das estruturas metálicas, essa deve ser realizada sob o aspecto estrutural e avaliando o aspecto da corrosão, da condição das ligações e da presença de trincas. Enquanto que a inspeção para a laje em concreto do tabuleiro, essa deve seguir o roteiro apresentado no Anexo B da norma NBR 9452 (ABNT, 2016).

Em relação as atividades de manutenção para a superestrutura da ponte mista foi mostrado que elas devem ser realizadas conforme o tipo de manutenção (preventiva ou corretiva), a frequência e os trabalhos a serem realizados. No caso das atividades de manutenção previstas para os elementos das estruturas metálica foi destacado que elas são realizadas com o objetivo de evitar principalmente a ocorrência da corrosão para as estruturas metálicas e que as ligações parafusadas e soldadas trabalhem corretamente. Já para a estrutura da laje em concreto do tabuleiro, as atividades de manutenção devem ser realizadas de modo a garantir a proteção das armaduras contra o ataque da corrosão, selagem de fissuras e de trincas e remendos em concreto.

\section{REFERÊNCIAS}

ASSOCIAÇÃO BRASILEIRA DE NORMAS TÉCNICAS. NBR 9452: Inspeção de pontes, viadutos e passarelas de concreto - procedimento. Rio de Janeiro, 2016.

BOLINA, F. L.; TUTIKIAN, B. F.; HELENE, P. R. L. Patologia de estruturas. São Paulo: Oficina de Textos, 2019.

DNIT - DEPARTAMENTO NACIONAL DE INFRAESTRUTURA DE TRANSPORTE. Manual de Manutenção de Obras de Arte Especiais - OAEs (Minuta). Rio de Janeiro, 2016. Disponível em: 〈http://ipr.dnit.gov.br/noticias/novas-normas-em-consulta-publica/minuta-manual-de-manutencao-oaes.pdf/view〉. Acesso em: 2 dez. 2019. 
DNIT - DEPARTAMENTO NACIONAL DE INFRAESTRUTURA DE TRANSPORTE. Publicação IPR 081: Tratamento de trincas e fissuras - Especificação de Serviço. Rio de Janeiro, 2006.

DNIT - DEPARTAMENTO NACIONAL DE INFRAESTRUTURA DE TRANSPORTE. Publicação IPR 083: Remoções no concreto - Especificação de Serviço. Rio de Janeiro, 2006.

DNIT - DEPARTAMENTO NACIONAL DE INFRAESTRUTURA DE TRANSPORTE. Publicação IPR 084: Tratamento da corrosão - Especificação de Serviço. Rio de Janeiro, 2006.

COSTA, F. G. Inspeção e avaliação nas estruturas metálicas - Pontes e Viadutos. Instituto de Engenharia de São Paulo. São Paulo, 2019. Disponível em: < https://www.institutodeengenharia.org.br/site/2019/09/12/material-tecnicoinspecao-e-avaliacao-de-pontes-e-viadutos-metalicos/>. Acesso em: 13 jan. 2020.

FONSECA, W. D. ASSIS. Proposta de manual de inspeção de pontes metálicas ferroviárias. Dissertação (Mestrado Profissional) - Universidade Federal de Ouro Preto, Escola de Minas - Departamento de Engenharia Civil. Ouro Preto, MG, Brasil, 2018.

MONTOYA, R. Manual de manutenção de pontes ferroviárias. São Paulo: Pini, 2016.

NYSDOT - NEW YORK STATE DEPARTMENT OF TRANSPORTATION. Fundamentals of Bridge Maintenance and Inspection. USA, 2008.

POÇAS, R. F. G. Gestão do ciclo de vida de pontes. Dissertação (Mestrado) - Universidade do Minho - Escola de Engenharia. Portugal, 2009. 